\title{
EL DERECHO REAL DE SUPERFICIE
}

\section{A don Ramón Serrano Suñer (*) \\ Carlos Cárdenas Quirós}

Al momento de redactar estas lineas, el Proyecto de nuevo Código Civil se encuentra en revisión, con el propósito de que sea promulgado y entre en vigencia a la brevedad.

Una de las instituciones que dicho Proyecto contempla es el derecho de superficie.

El texto que sigue, que actualiza conceptos vertidos en la tesis titulada "El derecho real de superficie en la doctrina, en la legislación civil peruana y en el derecho comparado" que el autor presentó para optar el grado de Bachiller en Derecho, no tiene otra pretensión que introducir al lector en el tema.

Conviene aclarar que el análisis extenso que se efectúa de la regulación que el Código Civil de 1936 brinda actualmente a la

(*) "El Derecho, que es rémora detestable y odiosa cuando, como reloj parado, marca una hora inamovible en su esfera, es la garantia insustituible para los valores personales cuando marcha a compás del tiempo y cuando sirve para abrir a cauce a la concepción del mundo y de la vida que tiene la generación que ha de cumplirlo". (Serrano Sufier, "Siete Discursos", pág. 115. Ediciones FE, 1938). 
institución superficiaria, tiene por objeto demostrar la necesidad de su reforma.

I. Introdución. Ideas Preliminares. Concepto del derecho de superficie

En principio se presume que cualquier construcción, plantación u obra existente encima o debajo del suelo pertenece al prepietario de éste. Los romanos decian que la propiedad no tenía limites en cuanto a su extensión, ni en altura, ni en profundidad. Se extendia: "cujust est solum, hujust est usque ad coelum et usque ad inferos", (hasta el cielo y hasta los infiernos).

El derecho de superficie constituye una derogación de la regla general "superficies solo cedit, quidquid" inaedificatur solo ce. dit", (la superficie cede al suelo, todo lo que en ella se edifica cede al suelo).

En efecto, aqui se da una propiedad separada de la propiedad del suelo. La ley y la doctrina admiten asi, que no siempre el suelo y la construcción forman un todo indivisible.

Conviene tener presente, como expresa Messineo (1) que, "por superficie no debe entenderse, el estrato (necesariamente su. tilisimo y en rigor, sin espesor) de la corteza terrestre, esto es. el suelo (o facies de la tierra) que está en contacto con el inicio del espacio atmosférico. Objeto del derecho de superficie, en sentido técnico, es por el contrario, lo que, estando incorporado al suelo (construcción), emerge del suelo; dicho en una sola palabra, es el sobresuelo (superfaciem)".

En virtud del derecho de superficie, el propietario del suele - dominus soli constituye sobre éste, un derecho a favor de un tercero (superficiario) que lo faculta a tener y mantener cons. trucciones sobre el mismo o por debajo de él. Se trata de un derecho de naturaleza real, merced al cual cobra virtualidad juridica la asi denominada propiedad superficiaria, cuyos alcances se explican más adelante.

(1) Manual de Derecho Civil y Comercial, tomo III, pág. 420. 
El derecho de superficie nació en Roma, como la gran mayoria de instituciones juridicas, pero no ha sido sino en los últimos tiempos cuando se le ha rescatado del olvido y adquirido su consagración definitiva en los Códigos modernos.

A mediados del siglo pasado, según lo anota Cirilo Martín Retortillo (2), "se dio por enterrada a la institución, debiéndose ello sin duda a que por las circunstancias de aquel momento, y tal vez por exigencias del pensamiento jurídico predominante, excesivamente individualista y liberal, no se estimó conveniente la adecuada regulación de una institución caduca y propia de tiem. pos ya lejanos, considerada como una reminiscencia feudal".

Empero, como lo menciona el mismo autor, citando a J. W. Jones, "cuando el problema de la vivienda se ha manifestado en forma aguda y la politica de fomentar la construcción ha buscado todos los cauces favorables, se cayó en la cuenta de que la superficie representaba uno de los mejores, de los más aptos para tal fin".

La Exposición de Motivos de la Ley Española del Suelo no se aparta de la verdad, cuando expresa que "el fomento de la edificación, no precisa, ni a veces aconseja, la enajenación de los terrenos; basta la constitución del derecho de superficie. La expzriencia extranjera muestra las intensas posibilidades de esta figura jurídica, que a la vez que facilita la construcción, evita la especulación de edificios y de terrenos, y reserva el aumento de valor para el propietario. De ahí que se admita la constitución deí derecho de superficie por entidades públicas y por particulares".

Nosotros estamos convencidos que el derecho de superficie resulta uno de los medios más idóneos y relevantes para resolver, y no tan solo para paliar, el grave problema que les significa a ias personas de economía limitada, la falta de vivienda, y en general, lo que constituye el déficit habitacional.

Este problema debe encararse de un modo realista. Nada mejor que hacerlo a través de una institución clásica, pero tam-

(2) El derecho de superficie según la Ley del Suelo, págs. 1 y ss. 
bién añeja, del Derecho Privado, que resucita felizmente cobrando nuevos brios debido a las exigencias de la vida moderna.

A este respecto, apunta significativamente Jerónimo González (3), que "la razón fundamental de este renacimiento la encontramos en el hecho de que el derecho de superficie es hoy uno de tantos medios utilizados para resolver el problema de la vivienda, que ahora entra en una fase aguda; problema moral, toda vez que la influencia de la habitación sobre el hombre se deja sentir poderosamente en sus sentimientos y hábitos; problema higiénico, del sol, luz, aire y salubridad; problema económico, sobre todo para las clases obreras, dada la enorme desproporción que en la actualidad existe entre el precio de los alquileres y los sueldos, salarios y remuneraciones de los que trabajan con el cerebro o con los brazos; problema eminentemente social, de cuya solución depende la independencia y organización de la familia, de un lado. y del otro, el más equitativo reparto de la natural "plus-valia" de los terrenos urbanizables, que las legislaciones del pasado siglo atribuyeron al propietario exclusivamente".

El éxito del derecho de superficie dependerá fundamentalmente de la regulación que se le ofrezca. Esta debe ser idónea y responder a la finalidad que con la institución se pretende alcanzar.

Definimos al derecho de superficie, como un derecho real, enajenable y trasmisible por sucesión, que confiere a su titular, durante un plazo determinado que no puede exceder al máximo fijado por la ley (se trata de un derecho temporal), la facultad de tener y mantener en terreno ajeno, sobre o bajo la superficie del suelo, una edificación en propiedad separada, obtenida mediante el ejercicio del derecho anexo de edificar (concesión ad aedificandum) o por medio de un acto adquisitivo de la edificación preexistente, o por contrato accesorio al de arrendamiento de un terreno.

De esta definición se derivan las notas caracteristicas del derecho de superficie:

(3) El derecho real de superficie, pág. 9. 
i) Es un derecho de naturaleza real, enajenable, y, también pur tanto, gravable y trasmitible mortis causa.

ii) Se trata de un derecho temporal.

iii) Otorga a su titular el derecho de tener y mantener una edificación en propiedad separada, por encima o por debajo del suelo, lo que constituye precisamente el objeto básico del derecho.

Merece la pena observar, como lo hace Puig Brutau (4), que "no puede ser objeto del derecho de superficie la colocacionn en el suelo de elementos transitorios y desmontables. La construcción superficiaria ha de ser de tal indole que, sin la existencia del derecho de superficie, lo edificado pasaria a ser propiedad del dueño del terreno, lo que no sucede con la colocación de elementos transitorios, que no están sometidos a la regla general de la accesion".

Sobre la base de la definición transcripta lineas arriba, po. demos también distinguir de un lado, el derecho de superficie y del otro, la propiedad superficiaria. Como con precisión anota Borzutzky (5), "una cosa es el derecho de superficie que es la expresión de aquella relación jurídica que permite al superficiario tener o mantener en terreno de otro la propiedad de la edificación, y otra, es la propiedad de esta edificación, cuya existencia hace posible el derecho de superficie, y que, por esto, si denomina propiedad superficiaria. No es que el derecho de superficie tenga una doble naturaleza, unas veces la propiedad de una edificación y otras el derecho a tener esta propiedad en terreno ajeno, pues lo primero es la propiedad superficiaria, y ln segundo es propiamente el derecho de superficie.

El derecho de superficie es el soporte jurídico de la propiadad superficiaria, y sólo puede ésta subsistir mientras subsista aquél, de suerte que, extinguido el derecho de superficie, desaparece la propiedad superficiaria como tal".

(4) Fundamentos de Derecho Civil, tomo III, vol. II, pág. 154.

(5) El derecho de superficie, pág. 19. 
Como lo expresamos más adelante, nosotros conceptuamos el derecho de superficie como un derecho real autónomo y sustan. tivo.

No son pocas las teorias que pretenden encuadrarlo dentro de los márgenes de uno u otro derecho real: Se le asimila asi al usufructo, a las servidumbres, a la enfiteusis, al arrendamiento y aun a la copropiedad.

La doctrina se divide como evidencia de lo afirmado, entre quienes conciben a la institución superficiaria como una desmenbración más del dominio, y quienes observan que respecto de ella coexisten dos propiedades sobre las cuales rigen los atributos clásicos del derecho de propiedad: el ius utendi, el ius fruendi y el ius abutendi.

El derecho de superficie se constituye por acto inter vivo;, o por acto mortis causa y a título gratuito $u$ oneroso. Se llega a admitir en ciertos casos que puede constituirse por usucapión. Al gunos también consideran a la expropiación como uno de los modos para constituirlo.

No hay duda, sin embargo, que la forma más frecuente de constitución del derecho de superficie es por acto inter vivos, es decir, mediante contrato, sea como resultado del derecho de construir o concesión ad aedificandum; es decir, cuando el propietario concede a una persona el derecho a edificar sobre el suelo o bajc él, adquiriendo asi el concesionario la propiedad de la construcción; o también, mediante la enajenación de una edificación preexistente o como consecuencia del contrato anexo al de arrendamiento de un terreno.

Es posible, igualmente, que se constituya un derecho de superficie de mayor elevación sobre un edificio que pertenece a una persona en propiedad superficiaria. A este derecho se le denomina derecho de sub-superficie o derecho de superficie de segundo grado.

Estimamos que ello es posible sobre la base de que no existe impedimento alguno para constituir derechos sobre derechos, correspondiendo dicha facultad a su titular. 
Se destacan en el derecho de superficie, tres tipos de elementos:

i) Elementos personales: el dominus soli y el superficiario.

ii) Elementos reales: el suelo y la edificación.

iii) Elemento formal: la inscripción como requisito constitutivo del derecho de superficie.

Un tratamiento exhaustivo del derecho de superficie debe consagrar legislativamente, cuando menos, las obligaciones y derechos más importantes del dominus soli y del superficiario. Consideramos que una de las principales obligaciones del primer nombrado es la de inhibirse de efectuar actos que imposibiliten o perturben el disfrute de su derecho al superficiario, desde el momento en que quede constituida la relación superficiaria.

Es indiscutible que en virtud de este derecho, el dueño del suelo pierde, si bien temporalmente, todo derecho, ya sea por encima del suelo o por debajo de él. Esto no excluye sin embargo que, dado que conserva la propiedad del suelo, pueda disponer de él libremente, sin que pueda resultar perjudicado el derecho de superficie establecido.

Como contraparte de la obligación mencionada, el superficiario tiene también las suyas. Así por ejemplo, está obligado a levantar la construcción inherente al derecho de superficie dentro del plazo pactado o, en su defecto, en el legal.

De otro lado, tendrá derecho a gozar de alguna otra partz del suelo, además de la necesaria que está referida al objeto dei derecho, si ofrece ventajas para su aprovechamiento; a disponer de él, a gravarlo con hipoteca, etc.

El derecho de superficie puede tener una duración temporal, indefinida o perpetua.

Los diversos ordenamientos civiles que admiten la existencia de la institución superficiaria, han previsto distintos plazos de duración, admitiendo algunos de ellos que sea perpetuo. Esta última 
opción es, empero, poco frecuente, aunque Códigos tan modernos como el Italiano de 1942 y el Portugués de 1967 la consagran.

Nuestro ordenamiento civil, que concibe al derecho de superficie como un usufructo sobre tierras edificables, le fija un plazo máximo de 99 años que consideramos excesivamente largo.

El derecho de superficie se extingue por muy diversas causas, algunas de las cuales son comunes a otros derechos reales principales.

Asi el derecho de superficie se extingue, entre otras razones:

i) Por el transcurso del plazo pactado o del legal.

ii) Por la resolución del título constitutivo.

iii) Por el abandono o la renuncia del superficiario.

iv) Otras causas:

a. Por confusión.

b. Por mutuo disenso.

c. Por destrucción de la cosa sobre o bajo la cual recaz.

d. Por perecimiento de la edificación en caso de pacto en tal sentido.

e. Por expropiación forzosa.

f. Por prescripción (no uso).

Ahora bien, hemos mencionado que el Código Civil de 1935 se refiere al derecho de superficie denominándolo usufructo sobre tierras edificables y legislándolo como una modalidad del usufructo. Conviene que pasemos a referirnos seguidamente a dicho tratamiento. 
II. El derecho de superficie en el ordenamiento juridico peruano

Comentario a las disposiciones contenidas en el Código Civil de 1936. Necesidad de su reforma.

El Código Civil de 1936, aún en vigencia al momento de redactar estas líneas, se refiere al instituto superficiario en sus artículos 958 y 959 .

Conviene destacar de su regulación, dos cuestiones:

La primera, que el Código legisla el derecho de superficie llamándolo no por su nombre usual, sino denominándolo "usufructo sobre tierras edificables".

Sobre esto opinamos que, aun cuando no existe en honor a la verdad, una manifestación expresa del Código en el sentido de qu: es el derecho de superficie lo que está regulado por los artículos 958 y 959 del mismo, y que la Exposición de Motivos del Proyecto de Libro Cuarto del Código Civil vigente, guarda silencio sobre el particular, del análisis de los preceptos mencionados y, principalmente, de sus antecedentes, podemos llegar a esa conclusión.

En efecto, expresaba el autor del Primer Anteproyecto sobre el Libro de los Derechos Reales, doctor Alfredo Solf y Muro. en el Memorando que presentó en la 148: sesión de la Comisión Reformadora del Código Civil Peruano de 1852, celebrada el miércoles 14 de abril de 1926, lo siguiente:

"El Anteproyecto contiene otra innovación, la del usufructo convencional en tierras útiles para la edificación, con el objeto de conferir la propiedad de los edificios al usufructuario del suelo, creando el llamado derecho de superficie.

Esta regla tiene por fin una necesidad sentida en nuestro medio, y en otros paises se ha empleado como medio de aumentar el número de habitaciones en las ciudades y fomentar las llamadas casas baratas" (6).

(6) Actas de la Comisión Reformadora del Código Civil. Fasciculo VI, pág. 58. 
El Anteproyecto en referencia reguló el derecho de superficie en el numeral 49, con el siguiente texto:

"Por actos entre vivos sólo podrá constituirse usufructo sJbre tierras edificables a efecto de que el usufructuario tenga un derecho de propiedad sobre los edificios que levanten en ellas.

Este derecho no podrá constituirse por más de 30 años y al término de ellos el edificio pasa a la propiedad del dueño de la tierra".

En la 198: sesión de la Comisión Reformadora del vierne:s 29 de abril de 1927, se aprobó el texto del Anteproyecto, inclusive su artículo 49, con algunas modificaciones. Asi a iniciativa del doctor Manuel Augusto Olaechea, se suprimió la palabra "sólo" y se sustituyó el número "30" por el de "99" (7).

En el segundo Anteproyecto del Libro Cuarto del Código Civil se lee el artículo 233, cuyo tenor literal es el siguiente:

"Por actos entre vivos podrá constituirse usufructo sobre tierras edificables a efecto de que el usufructuario tenga un derecho de propiedad sobre los edificios que levante en ellas. Este derecho. no podrá constituirse por más de noventa y nueve años, y al término de ellos el edificio pasa a la propiedad del dueño de la tierra".

El Proyecto de Código Civil presentado el 7 de marzo de 1936 al Ministro de Justicia del Gobierno del General Oscar R. Benavides, por los miembros sobrevivientes de la Comisión, pues a esa fecha ya habian fallecido el ilustre jurista y Presidente de la Comisión, doctor Juan José Calle y el preclaro alienista, docto: Hermilio Valdizán, regulaba el derecho de superficie en dos artículos, el 951 y 952 , cuyo texto transcribimos a continuación:

(7) Actas, VII, pág. 73

(8) Op. cit., pág. 275 . 
"Artículo 951"- Por actos entre vivos puede constituirse. usufructo sobre tierras edificables a efecto de que el usufructuari. tenga derecho de propiedad sobre los edificios que levante".

"Artículo 952" - Este derecho podrá constituirse a lo más pos noventa y nueve años, y pasado el término el edificio es de la propiedad del dueño del suelo".

La Ley No 8305 de 2 de junio de 1936 autorizó al Poder Ejecutivo para promulgar el proyecto de Código Civil preparado por la "Comisión Reformadora del Código Civil", introduciendo las reformas que estimara convenientes, de acuerdo con la Comisión que designara el Congreso Constituyente.

En atención a ello, el Proyecto fue sometido a la revisión de una Comisión nombrada por Resolución Suprema de 18 de junio de 1936. En las actas de las sesiones de dicha Comisión no aparece ninguna referencia a la institución que analizamos, ni a los artículos que la regulan.

El texto final del Código Civil promulgado por Decreto Supremo de 30 de agosto de 1936 en uso de la autorización contenida en la referida ley № 8305 y que entró en vigencia a partir del 14 de noviembre de ese mismo año, se ocupa de la materia como lo hemos mencionado ya, en los artículos 958 y 959 preceptuando. respectivamente lo siguiente:

"Artículo 958" - Por actos entre vivos puede constituirse usufructo sobre tierras edificables, a efecto de que el usufructuario tenga derecho de propiedad sobre los edificios que levante".

"Artículo 959"- El derecho a que se refiere el artículo anterior, podrá constituirse a lo más por noventa y nueve años, y pasado el término, el edificio será de la propiedad del dueño de? suelo".

La segunda cuestión se refiere a la circunstancia que el derecho de superficie no está legislado de modo independiente, como un derecho real, autónomo y sustantivo, sino como una modalidad del usufructo, y por ello to encontramos contenido en el titulo dedicado a este derecho real. 
En cuanto a esto, que en parte explica el silencio del Código para referirse de modo expreso al derecho de superficie, ello se jus. tifica porque el Código, al incluir a la institución en el título referido al usufructo, como lo hace también con los derechos de uso y habitación, se ha adscrito a la teoria heterónoma de la superficie, en virtud de la cual, se la entiende como una desmembración más del dominio. parecida al usufructo y similar a la enfiteusis.

El Código confunde pues el derecho de superficie con el usufructo, a pesar de las evidentes diferencias existentes entre amba: figuras, sobre todo en cuanto a su plazo de duración, al cual se refiere su artículo 959.

Dichos derechos reales son perfectamente diferenciables el uno del otro, desde que el primero, según nuestro Código, sólo puede recaer sobre tierras edificables, mientras que el segundo puede incidir sobre toda clase de bienes (artículo 925 del Código Civil); por la forma de su constitución, teniendo en cuenta que en nuestra legislación civil, el derecho de superficie sólo puede nacer por acto inter vivos, mientras que el usufructo nace en virtud de la ley, por acto inter vivos o mortis causa, y porque el usufructo es esencialmente un derecho que tiene como máximo la vida del usufructuario. El usufructo es un derecho vitalicio, aun cuando existe discusión en nuestro derecho sobre este particular debido a la defectuosa redacción del artículo 943 del Código Civil, mientras que el derecho de superficie puede extenderse más allá de la vida del superficiario, si bien puede acordarse libremente su constitución por el plazo de vida de aquél. Claro está, que si se vencen los 99 años a que alude el numeral 959 del Código, plazo máximo por el cual puede constituirse el derecho de superficie, y el superficiario no ha fallecido aún, el derecho se extingue automáticamente.

Igualmente debe notarse que mientras el derecho de usufructo otorga el aprovechamiento del bien a quien ejercita ese derecho, el derecho de superficie concede la propiedad sobre los edificios que se levanten, aunque sea por un plazo transitorio que no puede exceder el espacio de tiempo impuesto por la ley.

Adicionalmente, el usufructuario, a diferencia del superficiario, está obligado a respetar la forma y sustancia de la cosa, no 
pudiendo cambiarla. De otro lado, el usufructo, refiriéndose a ua edificio, alcanza al suelo, mientras el derecho de superficie tiene limitado su objeto a lo construido.

Son hechos relevantes de la regulación del derecho de supezficie en el Código Civil de 1936, las siguientes:

1) Se reconoce su calidad de derecho de naturaleza real.

Los antecedentes de esta consideración se encuentran en el Derecho Romano a partir del momento en que el Pretor ofreció una protección real a la institución mediante el interdicto de superficiebus y la actio de superficie.

Empero, el Derecho Romano no consagró al derecho de superficie como un derecho de naturaleza real, sino personal, a pesar de esos remedios de tipo real. A lo más lo consideró como un derecho en cosa ajena.

Todos los ordenamientos positivos que se ocupan de la institución la consagran definitivamente como un derecho de carácter real.

Su naturaleza real es el arma fundamental, como ha sostenido con acierto Borzutzky, para garantizar al superficiario la consecución de los fines propios de la relación, lo mismo respecto de los terceros para exigirles una abstención (de cualquier pertur. bación en el ejercicio de su facultad de construir), que del propietario del suelo, limitándole la utilización del mismo que permanece de su propiedad, aunque pueda realizar actos de disfrute compatibles con las facultades del superficiario.

Tanto el dominus soli como el superficiario gozan de la protección real inherente a su derecho frente a todos, respecto del suelo o de la construcción, según corresponda.

$Y$ es un derecho real, aun cuando no exista construcción de por medio. Tanto es cierto esto que, en principio, la destrucción de lo edificado no importa la conclusión de la relación superficiaria. 
El superficiario, como expresa Messineo, "puede construir la edificación por efecto del derecho que tiene sobre el suelo, derecho que le corresponde durante todo el tiempo, porque ha sido constituída la relación, aunque desaparezca lo construído".

2) Concede al superficiario un derecho de propiedad, sobre las construcciones que levante, que si bien es temporal, lo faculta a ejercitar los derechos inherentes al dominio, entre ellos el de disposición.

Conforme al artículo 959 del Código Civil de 1936, el plazo de duración máximo del derecho de superficie es de 99 años. Cabz preguntarse, ¿Porqué 99 años y no 100? Desde Roma el tope de 100 años era temido como perpetuo, aparentemente esa seria la razón para no extenderlo más allá. Empero, el Código Suizo asi lo establece sin ningún temor (cfr. su articulo 779.1).

El Código nacional no ha establecido un plazo mínimo de duración. Como es lógico debe entenderse que si se pacta un plazo de duración mayor que el indicado, éste deberá reducirse al establecido por la ley, por aplicación analógica de lo previsto por el artículo 950 del Código vigente.

El doctor Romero Romaña, ha afirmado que el plazo de 99 años "es tal vez demasiado largo, en que pueden suceder hasta tres generaciones, pudiendo ocurrir lo que aconteció con la enfiteusis, en que el contacto prolongado con la cosa engendra derechos que se quieren oponer después al propietario del suelo.

La situación es más grave, porque el derecho puede ser pactado entre particulares, ya que no hay limitación alguna en cl Código. Creemos - dice que entre particulares no debiera haberse aceptado tan largo plazo, el que sólo es admisible para el Estado o corporaciones oficiales.

En las Actas de la Comisión Codificadora se constata que al principio se pensó establecerlo sólo por 30 años como máximo".

En efecto, fue por sugerencia del doctor Manuel Augusto Olaechea que se varió ese plazo, sustituyéndolo por el de 99 que se mantuvo hasta el final. Consideramos que efectivamente el plazo 
previsto por el Código para la duración del derecho de superficie es muy dilatado. No es preciso un plazo tan extenso para favorecer su constitución. Estimamos que el plazo de treinta años, por el cual manifestamos nuestra preferencia es un término suficiente para que el superficiario y sus familiares gocen ampliamente de la edificación levantada, para contribuir al cumplimiento de los de la institución superficiaria. Treinta años es un plazo bastante extenso que no significa, como algún autor ha apreciado (9). "reducir la constitución del derecho, pues el interés del superficiario seria incuestionablemente menor". No puede negarse que el mencionado no es un plazo breve, por lo cual no cabe abrigar temores infundados sobre el particular".

Reducir el plazo previsto por el Código, tampoco significa ponerle trabas al derecho de superficie.

Consideramos que por su propia naturaleza, el derecho de superficie debe constituirse por un plazo amplio, como el propuesto; si bien no muy dilatado.

Es evidente que un plazo breve no responderia a sus fines. Tampoco es de su esencia ser perpetuo, desde que ello iria contra su principal propósito cual es el de promover la edificación. ¿Qué aliciente sería ello para el dominus soli o sus herederos?

No debe perderse de vista que en el Derecho Romano se exigia únicamente que fuera constituido por largo tiempo, sin imponer necesariamente su perpetuidad.

3) Como se ha anotado precedentemente, sólo puede constituirse por acto inter vivos, es decir mediante contrato. No puede establecerse en nuestro medio por disposición de última vo. luntad (testamento).

Compartimos la opinión de Arias Schreiber (10), en el sen. tido de que "rige igualmente la usucapion a través del principio

(9) Max Arias-Schreiber Pezet. Exposición y Comentario de los Derechos Reales en el Código Civil Peruano de 1936, tomo III, pág. 185.

(10) Op. cit., pág. 178. 
que la extiende a todos los derechos reales. Quien goza como superficiario sin serlo por alguna deficiencia de la convención, podrá convertirse en tal por obra del transcurso del tiempo (artículo 948 del Código Peruano vigente)".

Se ha afirmado que así puede ocurrir, por ejemplo, en el cass que se haya constituido el derecho de superficie por el tiempo de vida del superficiario. Su muerte determinó la conclusión del derecho. Sus herederos se dirá, se encuentran en aptitud de adquiri. por prescripción el bien objeto del derecho de superficie si transcurre el término que establece el Código en su artículo 871.

Nosotros opinamos en cambio respecto de este caso que, dado que conforme a la última parte del artículo 959 la reversión $d$ : la propiedad superficiaria se produce automáticamente, ipso jure, con lo cual dominus soli consolida la propiedad del suelo y de lo edificado, dichos herederos propiamente estarán usucapiendo suelo y edificación, pues ésta se le ha incorporado al recobrar vigencid plena el principio de accesión. La superficie cede al suelo al momento en que concluye el derecho por el transcurso del tiempo.

4) Como lo hemos anotado anteriormente, sólo puede constituirse sobre tierras edificables, es decir sobre predios urbanos. No puede constituirse por tanto sobre plantaciones como in admite el Código Portugués entre otras legislaciones.

Afirma Castañeda (11) sobre el particular, que la tierra so.ore la que se localice el derecho debe ser tierra edificable, "área urbanizada, no urbanizable, porque toda tierra es susceptible de ser urbanizada. Debe tratarse de solares $u$ otras porciones de suelo que tienen la calidad de urbanos, siendo de advertir que tal calidad no depende de su naturaleza, sino de su situación. No obstante tratarse de un huerto ubicado dentro de la ciudad, se trata incuestionablemente de tierra edificable. Por el contrario, la tierra donde se han levantado edificios que sirven de morada al propietario del fundo rústico, no es tierra edificable en el sentido a que se refiere el articulo 958 del Codigo Civil y menos inmueble urbano".

(11) Los derechos reales, tomo III, pág. 162. 
Dice Romero Romaña (12) por su lado, que no puede establecerse sobre las tierras rústicas. "De ser asi indica, constituiria una verdadera enfiteusis. La disposición obedece a que la institución sólo ha sido admitida por la finalidad de promover la edificación. Por eso no estamos de acuerdo con la opinión del doctor Riva-Agüero, en su discurso como Decano del Colegio de Abogados, al decir que se trata del derecho de enfiteusis, que nos vuelve remozado. El derecho de superficie no es una enfiteusis, sino un derecho diferente y autónomo".

Valga aclarar con relación a la referencia al doctor José de la Riva-Agüero y Osma, que su mención al tema, lo hizo en su discurso-memoria al dejar el cargo de Decano del Colegio de Abogados de Lima, el 18 de marzo de 1937. En dicho discurso indicó textualmente lo siguiente:

"Otro instituto añejo que nos vuelve remozado, es el censo enfiteńtico, abolido el año de 1911, y que hoy resucita y retorna, en los artículos 958 y 959 , vestido a la usanza legal inglesa, para facilitar las edificaciones, sin pago de mejoras. En esta modalidad tiene un plazo máximo de 99 años" (13).

La mención del doctor Riva-Agüero al derecho de superficie, como puede apreciarse, es indiscutiblemente injusta.

5) El derecho de superficie se circunscribe a los edificios, por lo que quedan al margen de aquél los elementos que no fueran tales.

Como acertadamente señala González (14) "pueden ser objeto del derecho superficiario las construcciones de cualquier especie, siempre que no estén afectos a una necesidad transitoria. Por este último motivo se excluian las tribunas, puestos, teatros, etc., que los magistrados o patricios hacian construir en las grandes fiestas y solemnidades".

(12) Derecho Civil. Los derechos reales, pág. 274.

(13) Revista del Foro, ańo XXIV, pág. 15.

(14) Cit. por Arias-Schreiber, op. cit., pág. 179. 
6) Constituye un quebramiento del principio clásico romano de la accesión inmobiliaria (superficies solo cedit), en virtud del cual todo aquello que se halla sobre el suelo, pertenece al dueño de éste. Los efectos de dicho principio se suspenden hasta el vencimiento del plazo acordado entre el propietario y el superficiario o el máximo legal. Como anotan Planiol, Ripert y Picard (15), "el derecho de superficie deroga esta regla, al separar la propiedad del suelo de lo que sobre él se halla".

7) Es un derecho temporal que al extinguirse determina la consolidación del dominio. Con ello se produce la desaparición de la duplicidad o desdoblamiento de propiedades existente hasta ese momento.

Observa Roca Sastre (16), que "el tránsito de la propiedad de la edificación al dominus soli constituye un fenómeno semejante al de la accesión, pues si el derecho de superficie paralizó el efecto atributivo de ésta, la paralización fue por todo el tiempo de duración del derecho de superficie, que constituia el obstáculo, de modo que una vez extinguido éste, recobra la accesión su poder de atribución y la propiedad de la edificación deja de ser una propiedad separada superficiaria y a ella se extiende la propiedad del terreno".

Respecto a la temporalidad del derecho de superficie, indica Arias-Schreiber (17) que "el derecho de propiedad que concede la superficie sobre los edificios levantados es temporal.

$Y$ no podía ser de otro modo, puesto que se necesita interesar al propietario del suelo con una consolidación que si bien él no la gozará sí la disfrutarán sus descendientes, y en general, quienes vayan adquiriendo el dominio de la superficie, en el tiempo. Conforme éste transcurre, mayor será el interés de los adquirientes, interés que no existirá de no producirse la consolidación antedicha".

(15) Tratado de Derecho Civil, tomo III, págs. 286 y ss.

(16) Derecho Hipotecario, tomo III, pág. 58.

(17) Op. cit., pág. 183. 
Ya que abordamos la temporalidad del derecho de superficie, conviene referir una criticable omisión del Código, relativa a la indemnización que deberia recibir el superficiario, por la edificación levantada, al concluir el plazo por el cual se pactó el mismo.

Creemos que el propietario del suelo se encuentra obligado, en principio, a indemnizar al antiguo superficiario por dicha construcción, pagándole su valor, salvo que exista un pacto distinto. Aun cuando el Código Civil nada precise sobre el particular, compartimos la opinión de Arias-Schreiber (18), en el sentido que "la solución que mencionamos es la que se deriva del principio que prohibe todo enriquecimiento indebido".

Por lo dicho causa extrañeza una aseveración tan tajante como la de Rodriguez Llerena (19) cuando estima que una vez vencido el término a que alude el artículo 959. pasa la propiedad de lo edificado al dueño del suelo o a sus herederos en el estado en que se encuentra "sin opción a indemnización alguna".

Es bueno prevenir, aun cuando el Código tampoco diga nada al respecto, que la reversión de las edificaciones al propietario del suelo, al concluir el plazo pactado o el legal, debe efectuarse sin gravamen o limitación alguna, por cuanto los que estableció el superficiario caducan al vencimiento del plazo.

Es claro, en nuestra opinión, sustentándonos en la regulación de la materia en la legislación comparada y en la doctrina en general, que el derecho de los acreedores pasará a incidir, cuando ello ocurra, sobre el valor de la indemnización que abonará el propietario al antiguo superficiario por la edificación levantada por aplicación de un principio similar al que informa un artículo como el 1017 del Código. Civil.

8) Es un derecho alienable y transferible, dado que, como anota Maisch von Humboldt (20) "el superficiario ostenta la propiedad de los edificios que ha construido, naturalmente con

(18) Op. cit., pág. 185.

(19) Código Civil, pág. 277.

(20) Los derechos reales, pág. 108. 
la limitación de que transcurrido el plazo, éstos revierten al señor del suelo. He aqui una diferencia notable con el derecho de uso, que no es un derecho cesible, y cuyo fundamento es la calidad personal del titular. En efecto, por ser gratuito $y$ constituir una liberalidad, el derecho de uso es un derecho personalisimo, y en consecuencia, incesible. En cambio, el derecho de superficie es netamente económico y por lo tanto oneroso, ya que el señor del suelo sólo. lo otorga con miras a conseguir determinadas ventajas, siendo en consecuencia trasmisible y enajenable como todos los derechos con fuerte carácter económico".

Debemos recordar que de acuerdo con el Código Civil, el derecho de superficie sólo podrá ser establecido por actos inter vivos, conforme taxativamente lo dispone su articulo 958. Sin embargo, ello no excluye en nuestro concepto que pueda ser constituido a titulo gratuito.

Consideramos que la regulación que brinda el Código Civil vigente al derecho de superficice es sumamente criticable, desde que suscribimos la teoria autónoma de la superficie que la distingue claramente de otros derechos reales similares.

En ella coexisten según nuestra opinión, dos propiedades, rigiendo sobre cada una de ellas, y de manera absoluta, los atributos clásicos del derecho de propiedad: el ius utendi, el ius fruendi y el ius abutendi. Precisamente, en vista de este último, el propietario del suelo y el superficiario, tienen derecho de enajenar libremente sus respectivos dominios, según ha quedado indicado precedentemente.

Como anota con certeza Arias-Schreiber, puesto que los legisladores de 1936 "son suscriptores de la teoria heterónoma, enclavando a la superficie dentro de las desmembraciones del dominio, rigen para ella las reglas del usufructo, en cuanto le son aplicables, teniendo siempre presente las fundamentales diferencias entre una y otras figura" (21). 
Empero, si bien ello justifica en algo el tratamiento que ofrece el Código vigente al derecho de superficie, también podemos afirmar sin temor a equivocarnos, que la institución no ha llegado a tener el desarrollo deseado precisamente por ser su regulación legal incompleta y defectuosa.

Como medio importantisimo para resolver el problema de la vivienda de las clases modestas (22) o como "solución del problema de la vivienda y de la habitación propia permitiendo que la iniciativa privada marche paralelamente al Estado y no haga recaer únicamente sobre éste el peso de tan grave cuestión" (23). es necesario, para una evolución idónea de dicha figura que se la legisle ampliamente.

Afirma Corvetto Vargas (24) que "esta institución está mal tratada por el Código Civil. Si los codificadores estimaron necesario crearla, no se explica porque lo hicieron en forma incompleta $e$ insegura, ya que la legislaron solamente en dos articulos, lo que a todas luces es insuficiente.

Muchos casos que se plantean en la legislación comparada no tienen como resolverse en nuestro derecho. Basta para ello leer los artículos que les dedica el Código Civil Italiano. La jurisprudencia de los Tribunales habrá de llenar este vacio".

Si en nuestro medio, prácticamente carece de aplicaciones, de ello es responsable la legislación civil vigente. Es un caso relevante, que constituye excepción a lo afirmado, el sistema de las concesiones administrativas, aun cuando es bueno indicar que dicho sistema surgió y se desarrolló durante la vigencia del antiguo Código en 1852.

Como consecuencia del sistema aludido, se construyó el Teatro Manuel A. Segura sobre un terreno del Concejo Provincial de Lima, o el Restaurante "El Zoológico" del ya desaparecido Parque Zoológico o el del antiguo Restaurante La Cabaña, que hoy es un teatro y que es de propiedad municipal.

(22) Jerónimo González, op. cit., pág. 93.

(23) Arias-Schreiber, op. cit., pág. 181.

(24) Manual Elemental de Derecho Civil Peruano, tomo II, págs. 332 y ss. 
Dice sobre el particular Corvetto Vargas (25) que si bien era una necesidad reconocer esta situación, y que se hizo muy bien en hacerlo asi, debió legislarse no dentro del usufructo, sino en título independiente.

Un fenómeno similar al que ocurre en nuestro país, por carecer el instituto supérficiario de una regulación adecuada, sucedió en Alemania hasta la promulgación de la tey de 15 de enero de 1919.

Explica Martin Wolff (26) en relación al particular que "la importancia práctica de la superficie es mayor de lo que se supuso al redactarse el Código Civil, y, en particular, mayor que la que tuvo la superficie del derecho común. Esta importancia se manifiesta especialmente por el servicio que presta al problema de la pequeña vivienda. Varias ciudades y algunos Estados conceden sistemáticamente solares en superficie a término en lugar de enajernalos, lo cual tiene las ventajas de evitar la especulación con edificios y terrenos, de facilitar el aumento del valor del suelo en favor de los propietarios (Estado, Municipios), hacerle posible el ejercer una influencia sobre la manera de construir, y procurar a las clases obrera y media la posesión de casas propias. A un desenvolvimiento más amplio de esta institución se oponia hasta ahora su insuficiente regulación legal".

Atendiendo a lo expuesto es que consideramos necesario propiciar una adecuada reglamentación legal del derecho de superficie, consagrando en primer lugar su autonomia; regulándolo en un titulo independiente, del modo que merece por su trascendencia económico-social; y completando las reglas del Código Civil de 1936 sobre la base de la doctrina y la legislación comparada.

Es seguro que legislándolo independientemente, podrán consignarse dispositivos tan completos como los que contienen Códigos modernos como el Italiano de 1942, el Portugués de 1967 o el Boliviano de 1.976, que prevén casos como los siguientes: construcción por debajo del suelo, hipoteca del derecho de superficie, suerte de los gravámenes constituídos sobre el mismo luego de su extin-

(25) Op. cit., pág. 331.

(26) Derecho de Cosas, pág. 2. 
ción; pago de una indemnización al superficiario por el edificio construido al vencer el plazo por el que el derecho fue constituido o transcurrido el término legal, forma y oportunidad del pago del canon superficiario, causas de extinción del derecho de superficie, etc.

La institución, por la trascendencia del próposito económico y social que la inspira, requiere, como ha señalado con certeza Elguera, de "formas y protección legal, para su franco desenvolvimiento".

Conviene mencionar, antes de concluir, que en este sentido el Proyecto de nuevo Código Civil constituye en nuestra opinión un innegable avance aunque ciertamente timido.

En efecto, en primer lugar, el artículo 1004 consagra en la Sección Tercera (Propiedad Predial) del Capítulo II (Propiedad) del Libro V (Derechos Reales), la regla según la cual "el subsuelo o el sobresuelo pueden pertenecer a propietario distinto que el dueño del suelo".

De otro lado, en el Capítulo III (Usufructo, Uso, habitación y superficie) se regula el derecho de superficie en dos articulos, cuyo texto transcribimos a continuación:

"Artículo 1072" - Puede constituirse el derecho de superficie, por el cual el titular es propietario temporal de los que construya en terreno ajeno. Este derecho no puede durar más de 30 años".

"Artículo 1073"- El derecho de superficie será tranmisible por acto entre vivos o por testamento, excepto cuando se haya constituido como personalisimo".

Debe destacarse particularmente el hecho de que el Proyecto opte por consagrar al derecho de superficie como un derecho real autónomo y que fije su duración máxima en 30 años.

Empero, consideramos que la definición que brinda el Proyecto de la institución deberia ser más precisa, destacándose las formas cómo puede constituirse. 
La regulación del Proyecto omite pronunciarse respecto a lo que ocurre al término del plazo; esto es, si lo construido pasa al dominio del dominus soli, con o sin obligación de éste de reembolsar su valor.

Tampoco se refiere a los derechos y obligaciones del superficiario y del propietario, ni a las causas de extinción del derecho. Estimamos que para lograr su libre ejercicio y eficaz desenvolvimiento, es preciso ofrecerle sin tener una regulación y protección legal adecuadas.

Como indica de Tomaso, "cuando un derecho recoge espontáneamente las necesidades económicas y tiene vida propia, la legislación no tiene más que reconocerlo para encauzarlo y darle las formas que el interés social requiera.

De lo contrario se coarta el desenvolvimiento juridico y de la vida económica, obligando a disfrazar situaciones para poderlas encajar en el molde de la ley".

Sólo asi podremos tener la firme esperanza de que el instituto superficiario resulte un medio capaz de obtener la reducción del déficit habitacional en nuestro pais. 